\title{
Odisha Spatial Data Infrastructure (OSDI) - Its Data Model, Meta Data and Sharing Policy.
}

\author{
P. K. Parida ${ }^{1, *}$, S. Tripathi ${ }^{2}$ \\ Odisha Space Applications Centre, India - pkparida@yahoo.com, sandeeptrip.ifs@gmail.com
}

Commission V, WG V/3

KEY WORDS : Common Standard, Non-Interopérability, NDSAP, National Map Policy, Remote Sensing Data Policy, Odisha Spatial Data Policy, Inclusive Gouvernance, Data Model, Meta Data, Sharing Policy

\begin{abstract}
:
Recognizing the potential utility and importance of a large quantity of spatial data generated using public funds by the Government Departments, organizations and institutions of the State for good governance and taking into consideration that most of such spatial data remains inaccessible to common citizen although most of such data may be unrestricted and not sensitive in nature and also most of such data generated at different State Government Departments do not have compatibility due to lack of common standards and noninteroperability and further taking note of that Government of India framed the "National Data Sharing and Accessibility Policy (NDSAP)", National Map Policy (2005) and "Remote Sensing Data Policy (RSDP- 2001 and 2011)" to spell out sharing principles of information generated using public funds, Government of Odisha has institutionalised "Odisha Spatial Data Infrastructure(OSDI)", in the line of National Spatial Data Infrastructure(NSDI)". The Government of Odisha gazetted "Odisha Spatial Data Policy (OSDP)" in 22nd August 2015, in the line of NDSAP, to institute a policy frame work to facilitate sharing of such Government owned data through OSDI, in open format, for supporting sustainable and inclusive governance and effective planning, implementation and monitoring of developmental programmes, managing and mitigating disasters and scientific research aiding informed decisions, for public good. The OSDI has already been operational and made live.

This paper highlights the Data Model, Meta Data Standard and Sharing Policy adopted in OSDI, apart from other institutional / operational issues in smooth grounding and operationalisation of the OSDI in a State framework.
\end{abstract}

\subsection{INTRODUCTION:}

\subsection{Project Background}

The proposed OSDI is a web-based system built to serve the user, spread over the internet and intranet. It is envisioned to act as a Spatial Data Clearinghouse and central repository of all spatial data (Satellite Data \& Geospatial Layers) of the state government. Backed by extensive OGC standard implementation, OSDI in turn will be linked to NSDI and all the users of the State as well as Bhuvan Portal of Department of Space (DOS) and other users outside will be able to search, find, view and download all relevant Geospatial Data relating to the state of Odisha. It is proposed to preferably keep the GIS Database servers of the individual Departments of Govt. of Odisha in their respective Departments only with connectivity to OSDI GIS server at State Data Centre (SDC), Odisha Computer Applications Centre. It will ensure to remove the concern regarding their propriety of database generated by the individual stake holder departments and in the other hand, the rest of stake holder departments of Govt. of Odisha and Govt. of India Departments will get spatial data by consuming OGC web-service. This enables a win / win situation for all the stake holders sharing spatial data through a Common gateway i.e. OSDI.

The server-side is envisioned to host the web enabled database for already existing serving spatial data. Departments will be able to run the web applications for different geo-web services on web browsers. Typically, the user will request information from an Internet server holding the data repository. Then the server will process the request and send the required information to the user. The server components, i.e., the web server/application server and the data server will form a part of the server architecture. Only authorized/registered staff will have access to the server application/ database. This architecture will be developed specifically for Internet applications for publishing spatial data. It would also meet server capacity needs as web site access demand increases. The Web Server will host Internet Information Server (IIS), application server for providing portal services. The database servers will host a RDBMS. A hardware firewall will check all the dataflow between the Web Server and the database server. The users of the system will access the web application. The database will be accessed by the web application only. This will provide a clear segregation of three different layers such as user interface, application \& business logic and database layers. It shall be based on a Service Oriented Architecture (SOA).

\subsection{Understanding}

Although the term spatial data infrastructure (SDI) is largely self-explanatory, the concept is complex and has attracted varying definitions. The Global Spatial Data Infrastructure (GSDI) Association has stated that spatial data infrastructures provide a basis for spatial data discovery, evaluation, and application, and include geographic data, metadata, framework, services, clearinghouse, standards, partnerships, and education and communication (GSDI 2006).

\footnotetext{
* Corresponding author
} 
The many definitions of SDI (Rajabifard et al. 2003) differ in emphasis and purpose, and no clear consensus on the concept of SDI and its constituting elements and principles exists. For instance, Masser (2005), and Budhathoki and Budic 2007) emphasise the following three areas that underpin all SDIs:

- Policy and organisation (organisational, institutional, management, financial, political, and cultural issues)

- Interoperability and sharing (backbone of SDIs)

- Discovery, access, and use of spatial data (main purpose of SDIs)

Based on the above definitions, the broad schematic structure of Spatial Data Infrastructure (SDI) is understood by Govt. of India and State Govts implementing SDIs as follows.

\section{(Fig.1) Elements of SDI}

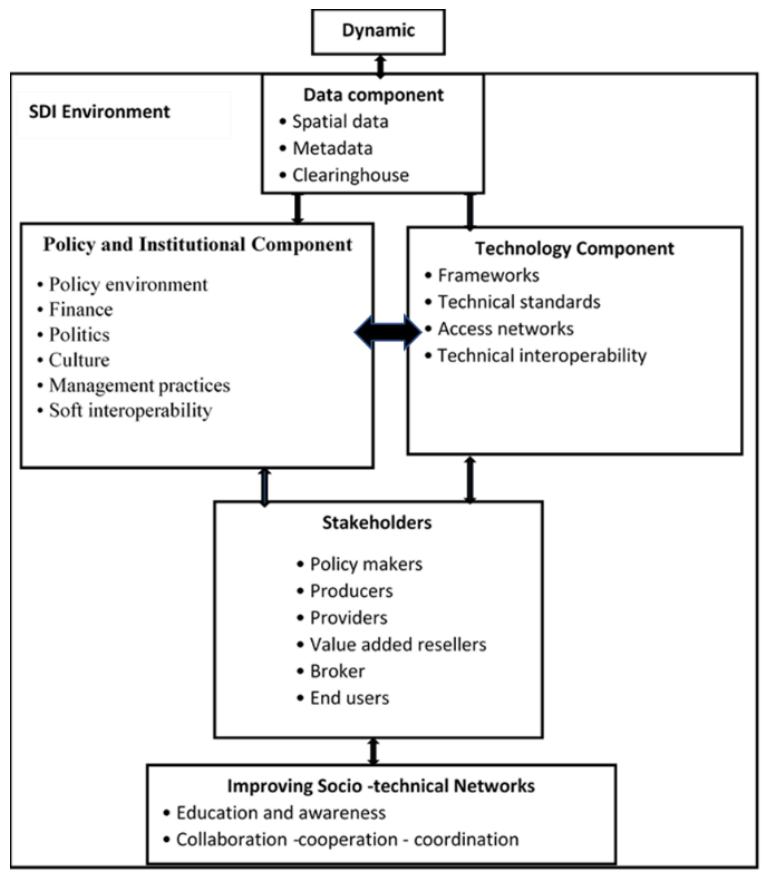

\subsection{Need for Spatial Data Infrastructure:}

The equitable, productive and sustainable developmental planning as well as good and inclusive governance need quality and authentic updated data and information. Different stakeholders of the Central/State Government have been generating large quantity of different forms of data and information with public funds. But this activity, most of the times, creates redundant data generated utilizing public money, time and human resources because of lack of information about such data and openness in sharing the datasets between different Government Departments and stakeholders. General public also seem to be deprived of accessing Government owned data from the concerned department although most of such data may be non-sensitive in nature and shareable, because Central/State Government departments do not generally publish catalogue or metadata of available data. Sharing of relevant data is imperative to facilitate effective and transparent governance. Further, due to lack of proper standards and interoperability of the data and information, interdepartmental sharing of such data and information become difficult and ineffective, apart from its access and use by common citizen.
Hence, there is a great need to evolve a protocol to facilitate easy accessibility, effective sharing and efficient utilization of the large amount of data generated and stored in disparate mode among the different entities of the Central/State Government. There is a need for both independent dedicated data enterprise systems in different Government departments as well as need to share critical and relevant information across the Departments with a central repository to make integrated data set available for informed decision making. This calls for adoption of a data policy in the Centre/state which conceptualize provisions for proper data management methods, defining data standards and processes for providing proactive and open access to such data facilitating formation of a National / State Spatial Data Infrastructure,

\subsection{Role of Spatial Data Infrastructure:}

Role of spatial data and associated non-spatial information is becoming critical in decision making and e-governance. Spatial data is a key component in citizen centric applications and tools that government and public enterprises use. It is understood that different departments/agencies are responsible to create/update the spatial information for the features/layers that they own. The key challenge that governments face is to ensure timely data creation/update and data interoperability between all departments at government level for good governance. Orissa Government has formulated Spatial Data Sharing Policies which govern the data ownership and exchange between departments and agencies.

\subsection{Initiation taken by Odisha Government:}

The establishment of "Odisha Spatial Data Infrastructure (OSDI)", concreted in the line of National Spatial Data Infrastructure(NSDI)", created vide SMP/25/003/05 Dated 13th June,2006 of Department of Science \& Technology, Government of India and Odisha Spatial Data policy gazetted by Govt. of Odisha on $22^{\text {nd }}$ August, 2015, facilitation of Spatial and Non-Spatial data sharing mechanism could be instituted through all the Govt. Departments and other institutions. The OSDI in terms of its vision, data formats, data model, metadata, various standards (metadata standard, exchange standard, and application protocol), network framework, macro- policies, data- pricing and dissemination policies, copyrights, and clearinghouse issues could be explicitly defined through high-level committees formed by Govt. of Odisha while framing the Odisha Spatial Data Policy. Odisha Space Applications Centre (ORSAC), the Nodal Agency of the Government of Odisha under Department of Science \& Technology, Department was entrusted to form OSDI under the frame work of Odisha Spatial Data Policy-2015.

\subsection{Objective:}

\subsection{Primary Objective:}

The primary objective of Odisha Spatial Data Infrastructure (OSDI) is to create a platform/application that enable departments to share/host the data. Also enable departments, citizens to discover, view, query and analysis of spatial data through a portal application/tools. The data would be made 
available in the form a OGC web service and can be consumed/used by departments and build their own applications/tools to help in day to day operations and decision making. Also, SDI application can have generic tools/decision support tools that can be used across departments.

\subsection{Basic Objectives of OSDI:}

The basic objectives of OSDI are compiled as follows:

- to facilitate storage as well as convenient and efficient access of data and its information in machine and human readable formats on the web portal in a standard and interoperable mechanism based on the SaaS version of Open Government Data (OGD) Platform.

- to facilitate a common protocol of updated data access and sharing of data with versions (or regression data as changes) in an integrated, automated, proactive and periodic manner.

- to facilitate broad use of all data and information including standardized geospatial datasets in planning, implementation and monitoring developmental programmes, disasters mitigation and scientific researches.

- to facilitate the accessibility of authentic data and information to all the stakeholders through an electronic network within the framework of various related Policies, Acts and Rules of Government of Odisha and Government of India made from time to time with a view to empower the citizen.

- to facilitate the timely availability of reliable geospatial data for the development, security and response in disaster management situations

\subsection{PROJECT AREA:}

\subsection{OSDI Geographic Domain:}

The geographic domain of OSDI covers the entire Odisha State having the geographic area as per Odisha Government Official Website is $155,707 \mathrm{~km} 2$. The Spatial Data Layers generated by the different stake holder departments of Govt. of Odisha lie within the Geographic area of the State.

\subsection{METHODOLOGY}

\subsection{Work Flows:}

The work flow adopted to form OSDI is given below.
- Selection Process of System Integrator for implementation of Odisha Spatial Data Infrastructure.

- Stakeholders of Odisha Spatial Data Infrastructure

- $\quad$ OSDI Needs Assessment Meeting with Stakeholders (Govt. Departments of Odisha).

- OSDI Real-World Model, Conceptual Model and Logical Model Design

- $\quad$ OSDI UML (Unified Modelling Language) diagram.

- OSDI Symbology Creation for each Feature Class

- Geo-Portal Migration Report

- $\quad$ OSDI Metadata Standard (BIS-16439 Metadata Standard)

- Implementation Architecture

- Some Key Features in OSDI Geoportal

- System Architecture

- $\quad$ Software Used

\subsection{Selection Process of System Integrator for implementation of OSDI:}

An Expression of Interest (EOI) was floated to invite the prospective bidders to participate in the bid to demonstrate their technology to comply the scopes of the Project. The Prospective bidders were shortlisted based on the general and technical criteria of EOI. The price bids were invited from the shortlisted bidders, where a Cost \& Quality Based Evaluation System was adopted to select the bidder scoring the highest scoring mark, based on the markings of both technical and financial scores in the weightage ratio of 70:30. The technical criteria with the scores adopted by ORSAC in the Quality \& Cost Based Evaluation System (QCBES) for selection of the System Integrator (SI) is given below.

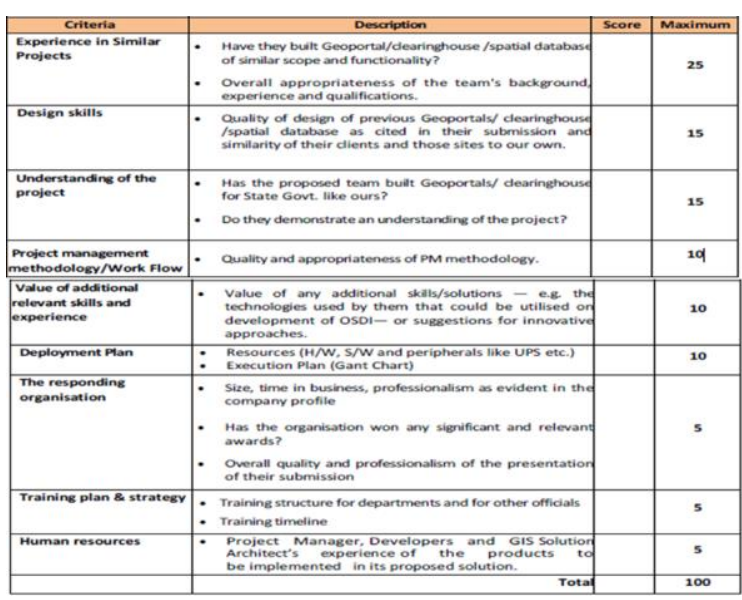

M/S Avneon India Pvt. Ltd. was emerged as the S.I to implement OSDI as per the scopes of Request for Proposal floated by ORSAC.

\subsection{Stakeholders of Odisha Spatial Data Infrastructure:}

All the Departments of Govt. of Odisha are covered as per Spatial Data Policy-2015 of Govt. of Odisha. Since the spatial 
data holding including metadata of individual departments are to be explored during the execution of the Odisha Spatial Data Infrastructure, however, it would be strived to publish at least two most important datasets of all the departments on the OSDI. The datasets will be published on priority basis of all the departments with the collection of metadata information in the first phase and it will continue in the subsequent phases. Some of the Key stake holder Departments are given below.

\begin{tabular}{|l|}
\hline Energy \\
Excise \\
Food Supplies \& Consumer \\
Welfare \\
Forest \& Environment \\
General Administration \\
Health \& Family Welfare \\
Higher Education \\
Housing \& Urban Development \\
Industries \\
\hline
\end{tabular}

\begin{tabular}{|l|}
\hline Panchayat Raj \\
Revenue \& Disaster \\
Management \\
Rural Development \\
School \& Mass Education \\
Science \& Technologies \\
ST \& SC Development, \\
Minorities \& Backward Classes \\
Welfare \\
Steel \& Mines \\
\hline
\end{tabular}

4.4 OSDI Needs Assessment Meeting with Stakeholders (Govt. Departments of Odisha):

One of the important steps in implementing such SDI platform/application is to understand data needs of different government departments and data ownership and sharing methods. ORSAC Project Team with the S.I conducted a Need Assessment Workshop to understand the data needs and mode of sharing the data owned by the stakeholder departments. A questionnaire is framed to take the inputs from the stakeholder departments and to understand the data needs of various departments and data available with the departments. Departments are requested to share the details of spatial data layers that they would like to use from SDI portal to help them in their day to day business and to share the data to OSDI for use of other stakeholder departments. The Need Assessment Workshop enabled the Project Team of ORSAC and S.I to model the SDI database, design the infrastructure and tools that suits all the department needs.

Also, the discussion/questionnaire included assessing application/tools that department would like to develop using the spatial data. Departments requested to share their application needs, so that the data could be modelled in line with application requirements. This procedure enabled sizing the infrastructure keeping the tool development needs of departments in mind. The screen shot of the part of the Need Assessment Questionnaire is given below as Fig.3.

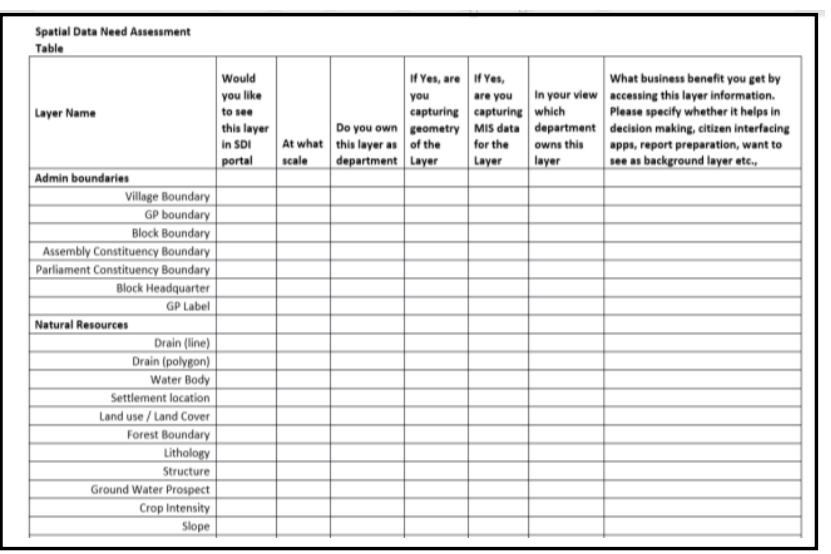

\subsection{OSDI Real-World Data Model, Conceptual Model and Logical Model Design:}

Needs Assessment Format were duly filled and submitted by Stakeholder Departments (Government Departments of Odisha). Then a Real-World Object Model consisting of Feature Dataset, Feature Class Name, Sub elements of each Feature Class was prepared according to the necessity of each Stake holder. A screen shot of the Real-World Data Model of Administrative Boundaries is given below as Fig.5.

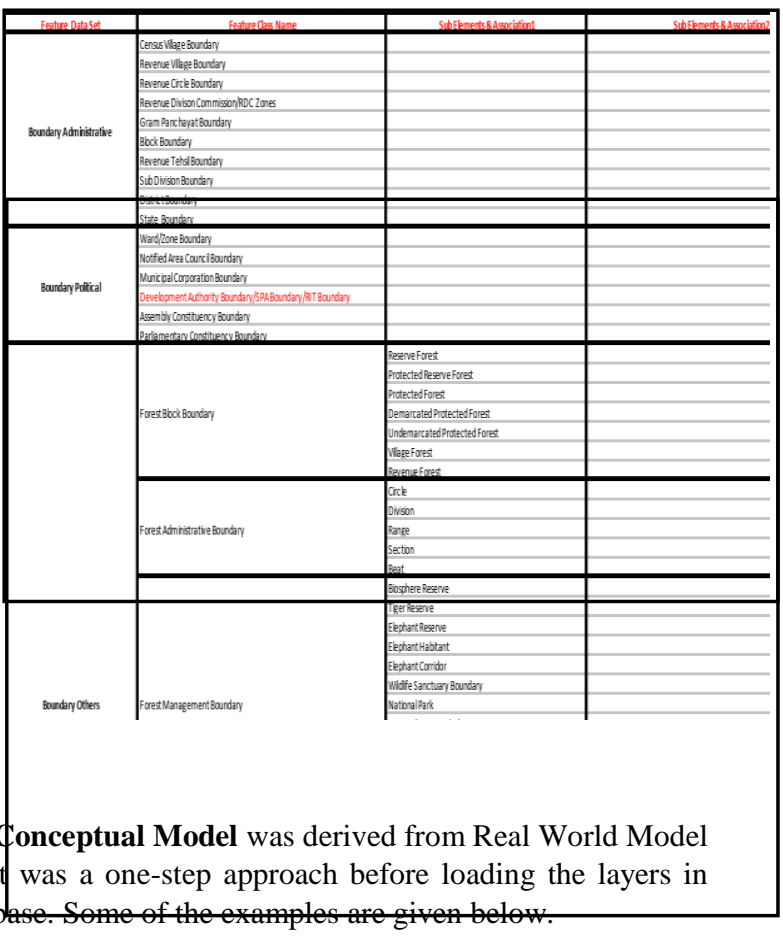

Category Name: - Boundary

Others

Layer Name: - Police

Boundary

Feature Type: - Polygon

Sub Type: - Division

Boundary

Sub_Division_Boundary

The Logical Model depicts the layer details which consists of Layer Name, Feature type, Field Name, Field Type, Field Length and Lookup values. The logical model of the data sets was generated by the S.I taking the conceptual data models of the database. An example of the logical model is given below. 


\begin{tabular}{|c|c|}
\hline \multicolumn{2}{|c|}{ Layer Name: - Police_jurisdiction } \\
\hline \multicolumn{2}{|c|}{ Feature Type: - Polygon } \\
\hline Field Name: - & Type \\
\hline Field Type: - & String \\
\hline \multicolumn{2}{|c|}{ Field Strength: - 30} \\
\hline \multicolumn{2}{|c|}{ Lookup values: - Police_Range Boundary } \\
\hline & Police_Dist_Boundary \\
\hline & Sub_Division_Boundary \\
\hline & Police_Station_Boundary \\
\hline & Out_Post_Boundary \\
\hline
\end{tabular}

\subsection{OSDI UML (Unified Modelling Language) diagram:}

The UML Model of all the layers were generated where relationships among the primary attribute and other secondary attributes of the feature data set were incorporated. An UML model of Administrative Boundary of OSDI is given below as Fig.6.

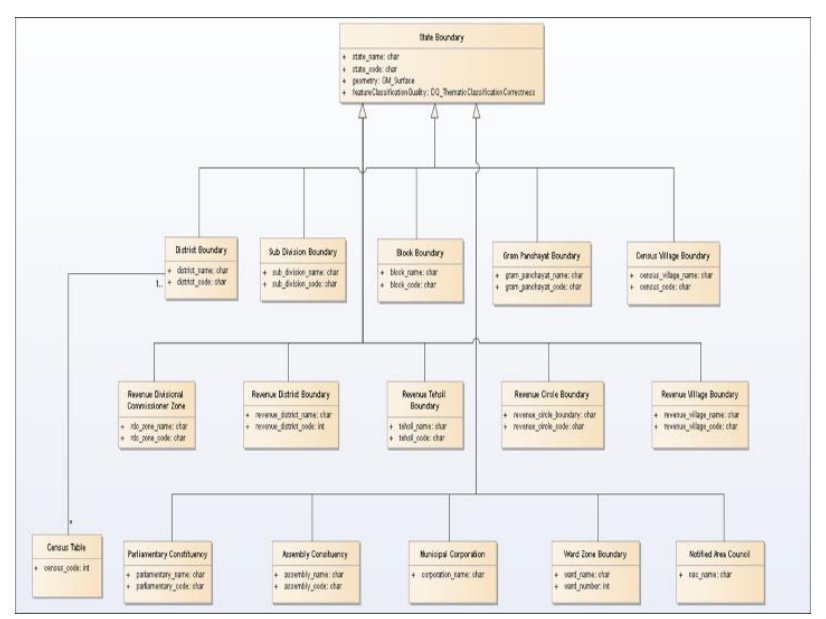

\subsection{OSDI Symbology Creation for each Feature Class:}

Symbology/Legends are prepared according to the Standard Proposed by National Remote Sensing Centre (NRSC), Indian Space Research Organisation (ISRO), Department of Space (DOS), Government of India for each layer/feature class under different National Projects executed jointly with ORSAC and other State Remote Sensing Centres. some Symbology/Legends are created by ORSAC while executing State Level Projects in consultation with the Stakeholder Government Department. A screen shot of Symbology/legend is given below as Fig.6.

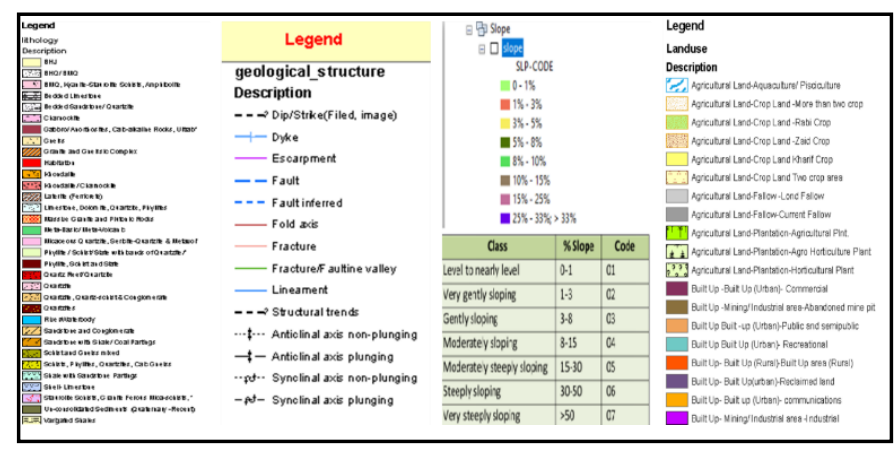

\subsection{Geo-Portal Migration Report:}

This Report was prepared after Migration of each Feature Class and the number of Features that loaded in the Central Database Server according to database schema following the UML diagram. The screen shot of the part of the Migration Report is given below as Fig.7.

\begin{tabular}{|c|c|c|c|}
\hline \multicolumn{4}{|c|}{ OSDI Data Migration Report } \\
\hline s No. & Feature Class & Migration Status & Feature Count \\
\hline 1 & block_boundary & Completed & 314 \\
\hline 2 & census_village_boundary & Completed & 53,812 \\
\hline 3 & district_boundary & Completed & 30 \\
\hline 4 & gram_panchayat_boundary & Completed & 6,677 \\
\hline 5 & state_boundary & Completed & 1 \\
\hline 6 & sub_division_boundary & Completed & 58 \\
\hline 7 & police_jurisdiction & Completed & 0 \\
\hline 8 & tribal_cluster & Completed & 16 \\
\hline 9 & tribal_itda & Completed & 22 \\
\hline 10 & tribal_mada & Completed & 54 \\
\hline 11 & tribal_primitive & Completed & 17 \\
\hline 12 & assembly_constituency & Completed & 147 \\
\hline 13 & parliamentary_constituency & Completed & 21 \\
\hline 14 & geological_structure & Completed & 164,497 \\
\hline 15 & lithology & Completed & 365 \\
\hline 16 & geomorphology & Completed & 58608 \\
\hline 17 & lulc_10k & Completed & 586271 \\
\hline 18 & lulc_nris_50k & Completed & 298299 \\
\hline 19 & lulc_nrsc_50k & Completed & 363382 \\
\hline 20 & slope & Completed & 2967364 \\
\hline 21 & major_soil & Completed & 82,788 \\
\hline 22 & soil & Completed & 0 \\
\hline 23 & canal & Completed & 3,960 \\
\hline 24 & drainage & Completed & 251,675 \\
\hline 25 & lakes & Completed & 0 \\
\hline 26 & reservoir & Completed & 0 \\
\hline 27 & rivers & Completed & 359 \\
\hline 28 & tank & Completed & 0 \\
\hline 29 & railway_station & Completed & 244 \\
\hline 30 & railwayline & Completed & 97 \\
\hline 31 & roads & Completed & 328558 \\
\hline 32 & basin & Completed & 199 \\
\hline 33 & catchment & Completed & 212 \\
\hline 34 & micro_watershed & Completed & 20,259 \\
\hline 35 & mini_watershed & Completed & 7,592 \\
\hline 36 & region & Completed & 187 \\
\hline 37 & sub_catchment & Completed & 258 \\
\hline 38 & sub_watershed & Completed & 3,951 \\
\hline 39 & watershed & Completed & 426 \\
\hline
\end{tabular}

\subsection{OSDI Metadata Standard (BIS-16439 Metadata Standard)}

A metadata standard is a requirement which is intended to establish a common understanding of the meaning or semantics of the data, to ensure correct and proper use and interpretation of the data by its owners and users. To achieve this common understanding, a number of characteristics, or attributes of the data have to be defined, also known as metadata. NSDI under Department of Science \& Technology, Govt. of India published Metadata Version 2 in August 2009 for facilitating other State Centres to use the Metadata standard for seamless integration with NSDI. Now Govt. of India has come out with Indian Standards of Meta Data i.e. IS-16439 which is similar to ISO - 19115. A screen shot of part of filled in Metadata of Geomorphology Feature Dataset is given below as Fig.8. 


\begin{tabular}{|c|c|}
\hline 1. Name of the Dataset: & Natural Sources \\
\hline 2. Name of the Data: & GEOM \\
\hline 3. Theme: & Study of land forms \\
\hline 4. Keywords : & Geomorphology \\
\hline 5. Access Constraints: & Unrestricted/Open/As per OSDI Data Desse imation Policy \\
\hline 6. Use Constraints: & Unrestricted/Open/As per OSDI Data Desse imation Policy \\
\hline 7. Purpose of Creating Data: & As part of preparation of Natural Sources Laver for Odisha Stat \\
\hline 8. Data Type: & Vector Data(Shape File) \\
\hline 9. Agency Name: & ORSAC \\
\hline \multirow{2}{*}{\multicolumn{2}{|c|}{ 11. Metadatalocoale: }} \\
\hline & \\
\hline \multicolumn{2}{|l|}{ (2) Citation information } \\
\hline 9. Data Prepared by : & ORSAC \\
\hline 10. Original Source: & LISS-III \\
\hline 11. Source Scale and Date: & $1: 50,000$ \\
\hline 12. Mapping year: & 2006 \\
\hline 13. Digitizing vear: & 2006 \\
\hline 14. Survey year: & $2006-07$ \\
\hline 15. Lineage: & Not Applicable \\
\hline 16. Associated Project preparing the data & Not Applicable \\
\hline 17. Associated Publications : & Not Applicable \\
\hline 18. Email : & Not Applicable \\
\hline 19. Affiliation: & State Govt. \\
\hline 20. Corporate Name: & Not Applicable \\
\hline 21. Corporate Address: & Not Applicable \\
\hline \multicolumn{2}{|l|}{ (3) Contact information } \\
\hline \multirow{2}{*}{ 22. Contact Person: } & \\
\hline & $\begin{array}{l}\text { Facility Incharge } \\
\text { ODISHA SPACE APPLICATIONS CENTRE (ORSAC) }\end{array}$ \\
\hline $\begin{array}{l}\text { 23. Organization: } \\
\text { 24. Mailing Address: }\end{array}$ & $\begin{array}{l}\text { Plot no. 45/48 (Part), Jayadev vihar, Near G opa bandhu Academy } \\
\text { of Administration Unit-16 }\end{array}$ \\
\hline \multirow{2}{*}{\multicolumn{2}{|c|}{ (6) Coverage information }} \\
\hline & \\
\hline 32. Coverage.x.min: & Left : $81.388722 \mathrm{dd}$ \\
\hline 33. Coverage.x.max: & Right : $87.485997 \mathrm{dd}$ \\
\hline 34. Coverage.y.min: & Bottom: $17.812462 \mathrm{dd}$ \\
\hline 35. Coverage.y.max: & Top : $22.568021 \mathrm{dd}$ \\
\hline 36. Coverage.tlate: & Not Applicable \\
\hline 37. Coverage.t.early : & Not Applicable \\
\hline 38. Coverage.PlaceName: & Odisha \\
\hline 39. Coverage.PeriodName: & Not Applicable \\
\hline 40. Coverage.spatial.resolution: & $1: 10,000$ \\
\hline \multirow{2}{*}{$\begin{array}{l}\text { 41. Coverage.spatial.georeference: } \\
\text { (8) Abstract data information }\end{array}$} & GCS WGS 1984, Datum: D WGS 1984 \\
\hline & (8) Abstract data information \\
\hline 62. MD Metadata.identification Info: & Geomorphology \\
\hline \multicolumn{2}{|l|}{ (9) Metadata date stamp } \\
\hline 63. MD Metadata date Stamp: & $2006-07$ \\
\hline
\end{tabular}

\subsection{Implementation Architecture}

The implementation architecture for OSDI is given below as Fig.9.

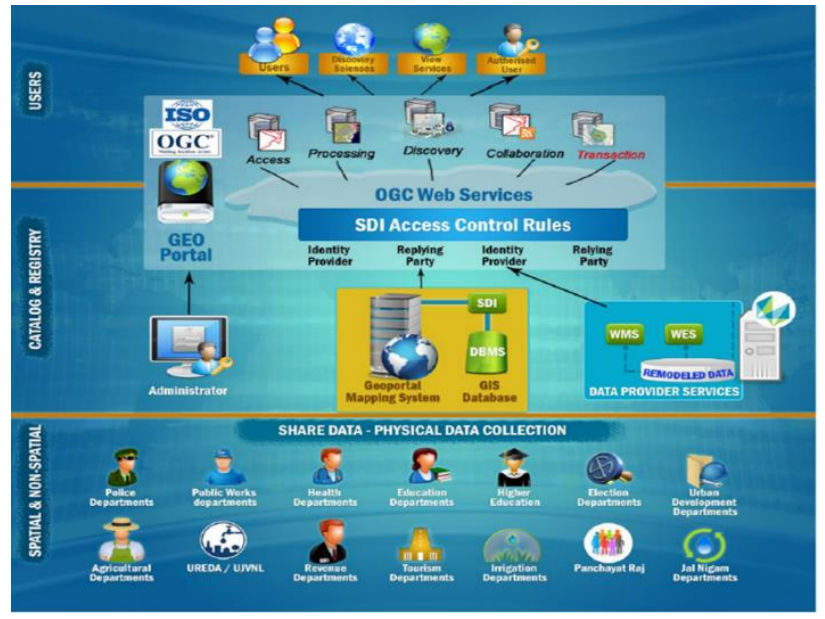

\subsection{Some Key Features in OSDI Geoportal:}

Some of the key features of OSDI Geoportal are given below.

- $\quad$ OGC Services

- $\quad$ DSS Tools

- MAP Services

- Spatial Services

- Map Catalogue

- Map Gallery

\subsection{System Architecture:}

The System Architecture adopted in OSDI is given below as Fig.10.

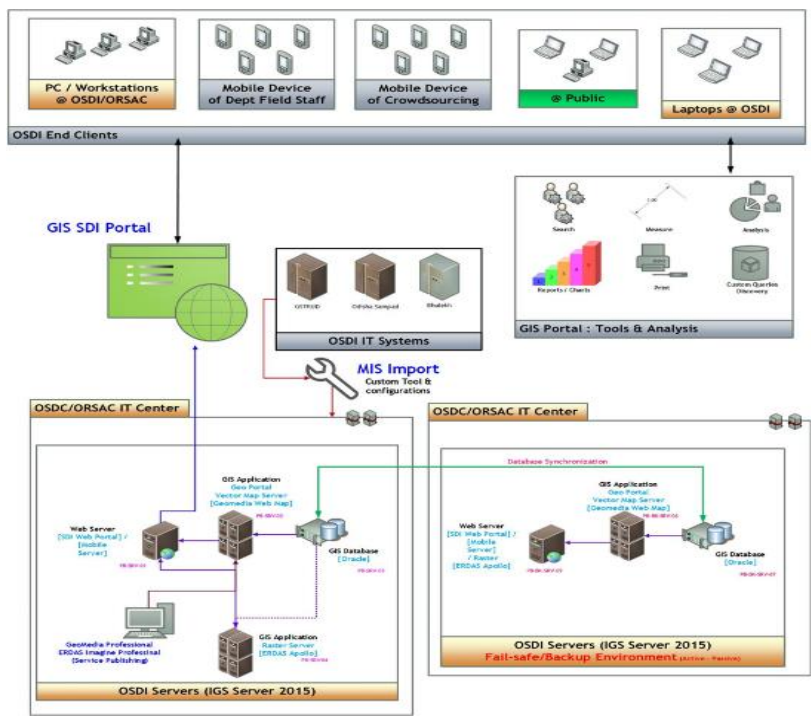

\subsection{Software Used:}

Following are the software Technology used in OSDI.

- IGS Server 2018: Professional

- Geomedia Web Map

- ERDAS Apollo Server

- ERDAS Imagine Professional

- Geomedia Professional

- $\quad$ Postgres Server (RDBMS) - Enterprise version

\subsection{SHARING MECHANISM AS DRAFTED IN ODISHA SPATIAL DATA POLICY-2015:}

All Departments will prepare and publish on their website the list of all data held by them. Further, any data designated as non-shareable (negative data) must be notified and published separately on their website within three months of notification of State Data Policy. However, such classification of nonsharable data would be subject to the approval by the State Level Steering Committee and also to be periodically reviewed by the State Level Steering Committee. All the spatial data would be stored in the open, WGS-84 datum with WGS-84 spheroid format along with all its attribute data to facilitate easy access and sharing of such data.

It would be incumbent upon all the concerned Departments to maintain and update and standardize such data in a periodic 
manner to facilitate easy and uninterrupted access to these data by all the Government Departments and bona fide users as per the conditions laid down under the data policy. The data generated by Government Departments are to be in the following data access structure: -

\subsection{Open Access:}

Access to data generated from public funding should be easy, timely, user friendly and web based without any process of registration/authorization.

\subsection{Registered Access:}

Datasets which are accessible only through a prescribed process of registration/ authorization by respective departments/ organizations will be available to the recognized institutions/ organization/ public users, through defined procedures.

\subsection{Restricted Access:}

Data declared as restricted under Government of India/Government of Odisha relevant policies will be accessible only through proper authorization.

\subsection{Results and Discussions:}

To facilitate easy access and sharing of data, a State of the art data warehouse, data archive with Online Analytical Processing (OLAP) capabilities and Open Application Protocol Interface is needed. To cater this need and for appropriate/uniform management of non-spatial/geospatial data contents of all the Departments, Odisha Spatial Data Infrastructure (Odisha-SDI) is formed. The Odisha Spatial Data Infrastructure after made live on $30^{\text {th }}$ April, 2018 has now become the repository of data of various Departments/ Organizations/ Agencies/ Autonomous bodies as a part of State service delivery gateway. The utilities of Odisha Data Centre and Odisha State Wide Area Network (OSWAN) has now become backbone for the connectivity with the Stakeholder Departments. The Stakeholder Departments are now getting the following benefits from OSDI Geoportal Clearing House.

(a) User friendly interface.

(b) Dynamic/ Pull down menus.

(c) Complete Metadata

(d) Search based Report.

(e) Cyber secured web access

(f) Bulletin board

(g) Parametric and Dynamic report in exportable format.

The stakeholder departments of Government of Odisha are now provided with a GIS Application format to provide at least two GIS Applications which will be useful to integrate in their business work flow in day to basis for taking quick decision based on the geospatial scenarios.

This paper will be also useful to other States and Institutions in general who are in the pipeline to generate Spatial Data Infrastructure (SDI) by following the work flows adopted by ORSAC.

A few of the applications available for the Stakeholder Departments of Government of Odisha under OSDI Geoportal are placed below to open up further applications interfaces by the User Communities.

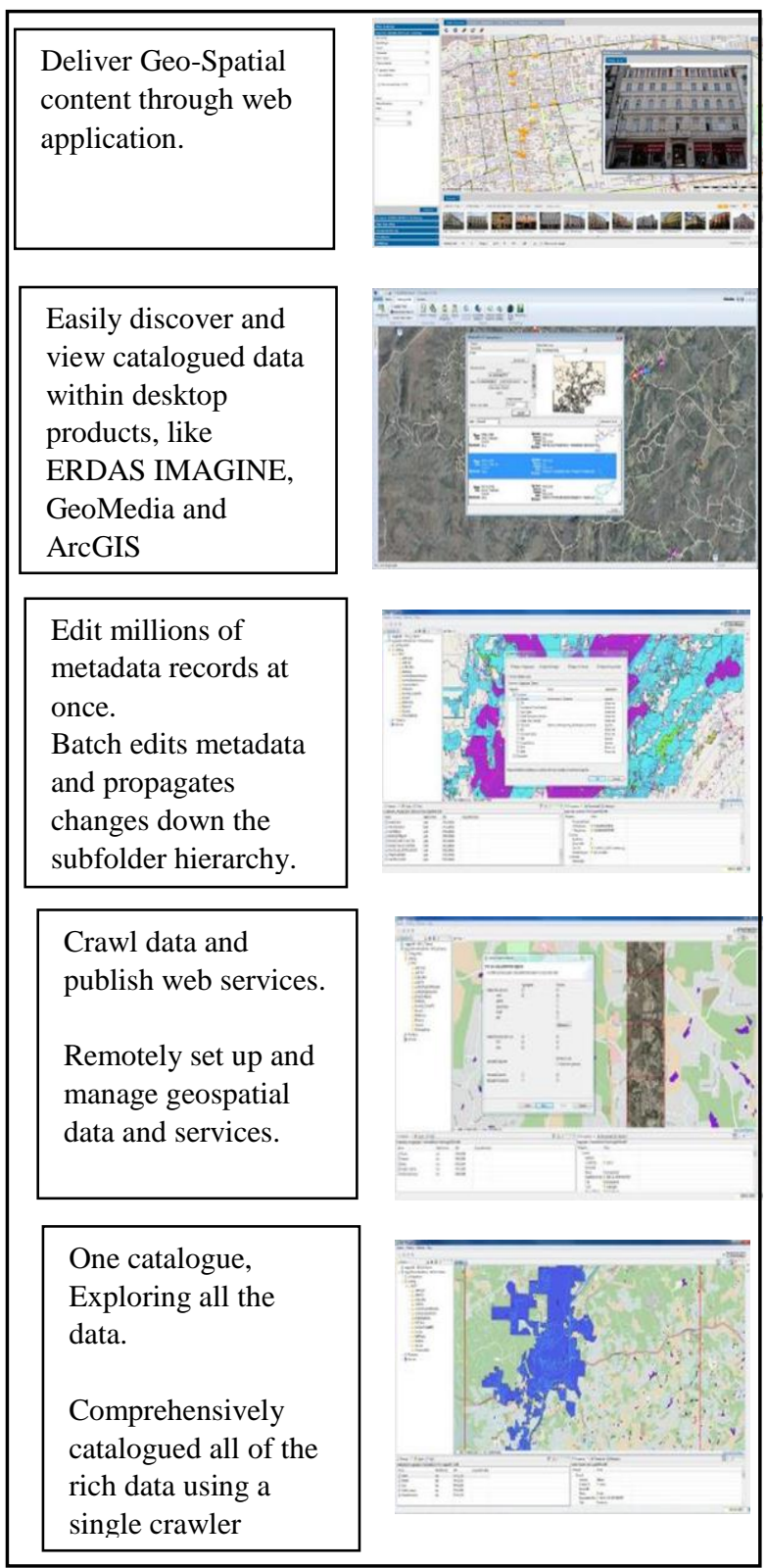

\section{REFERENCES}

Bardach, E. (1998). Getting Agencies to Work Together: The Practice and Theory of Managerial Craftsmanship. Washington, DC: Brookings Institution Press.

Bishr, Y. (1998). Overcoming the Semantic and Other Barriers to GIS Interoperability, International Journal of Geographical Information Science, 12 (4): 299-314.

Broom, L, P. Selznick, and D. Broom-Darroch (1981). Sociology, 7th edition. New York: Harper and Row.

Budhathoki, N.R. and Z.N. Budić (2007). "Expanding Spatial Data Infrastructure Knowledge Base in Research and Theory," in Harlan Onsrud (Ed). Advancing Spatial Data Infrastructure Concepts. California: ESRI Press. 
Cameron, D. (2001). The Structures of Intergovernmental Relations. Oxford: Blackwell Publishers.

de Man, W.H.E. (2000). Institutionalisation of Geographic Information Technologies: Unifying Concept, Cartography and Geographic Information Science, 27 (2): 139-152.

de Man, W.H.E. (2006). Understanding SDI: Complexity and Institutionalisation, International Journal of Geographical Information Science, 20 (3): 329-343.

DST (2005). National Map Policy. New Delhi: Department of Science and Technology, Government of India, at: http://dst.gov.in/, (accessed 13 July 2005).

Enemark, S. and I. Williamson (2004). Capacity Building in Land Administration: A Conceptual Approach, Survey Review, 39 (294): 639-650.

Feeney, M.E.F. (2003). "SDIs and Decision Support", in Ian Williamson, Abbas Rajabifard, and Mary-Ellen F. Feeney (Eds.). Developing Spatial Data Infrastructures: From Concept to Reality. Boca Raton: CRC Press, pp. 195-210.

Georgiadou, Y. and R. Groot (2002). Policy Development and Capacity Building for Geo-Information Provision: A Global Goods Perspective, GIS@ development: The monthly magazine on geographic information science, 6 (7): 33-40.

Georgiadou, Y., S.K. Puri and S. Sahay (2005). Towards a Potential Research Agenda to Guide the Implementation of Spatial Data Infrastructures: A Case Study from India, International Journal of Geographical Information Science, 19(10): 1113-1130.

Giff, G. (2006). "The Value of Performance Indicators to Spatial Data Infrastructure Development", Proceedings of the GSDI-9 Conference, Santiago, Chile, November 6-10.

GOI (2003). NSDI Metadata Standards, ISRO-NNRMS-TR104-2003, Version 3. New Delhi: Government of India.

GOI (2006). Resolution No. SMP/25/003/05 Government of India, Ministry of Science and Technology, Department of Science and Technology, New Delhi.

Groot, R. (2001). Reform of Government and the Future Performance of National Surveys, Computers, Environment and Urban Systems 25 (4-5): 367-87.

Grus, L.J.C. and K.B. Arnold (2007). Multi-view SDI Assessment Framework, International Journal of Spatial Data Infrastructures Research, 2007 (2): 33-53.

GSDI (2006). What are Spatial Data Infrastructures, GSDI Newsletter,8. at: http://gsdi.org/newsletters/GSDI/GSDInewsletterApr06.pdf. 